\title{
Restoration of spawning grounds for trout and grayling in the river High-Rhine
}

\author{
M. Zeh* and W. Dönni
}

Swiss Federal Institute for Environmental Science and Technology (EAWAG) and Swiss Federal Institute of Technology (ETH), Limnological Research Center, CH-6047 Kastanienbaum, Switzerland

Key words: Rhine, siltation, clogging, habitat restoration, salmonids, equilibrium diffusion technique, porewater samplers.

\begin{abstract}
In January $199010 \mathrm{~m}^{3}$ of washed gravel (grain size $16-50 \mathrm{~mm}$ ) were introduced in an impounded section of the River High-Rhine to test its potential as a spawning ground for salmonids. The process of infiltration of fine sediments into the gravel and subsequent clogging was monitored for three years. Levels of clogging of the gravel matrix were estimated and ranged from slight to moderately-heavy. The degree of clogging was lower in winter than in summer. Since no bedload transport was observed during the study period, flood events could wash out sediments from the top layer of the gravel bed only. An equilibrium diffusion technique using porewater samplers was employed to measure oxygen concentrations within the interstitial space during the spawning period of Thymallus thymallus (April), Salmo trutta fario and Oncorhynchus mykiss (December till February). Oxygen concentration decreased with increasing depth and during the course of the study period. Oxygen concentrations measured as a reference in the interstitial of the confluence of the river Glatt were considerably lower than those of the new gravel bed. A wide range of $\mathrm{O}_{2}$ concentrations was found in winter $1991 / 92$ and in spring 1992 . This could be explained by the heterogeneous microstructure of the substrate. Successful embryonic and larval development of grayling in the gravel bed was observed in spring 1991 and 1992. However, no eggs or larvae of brown trout or rainbow trout were found. Habitat restoration projects for salmonids in impoundments of the High-Rhine are critically discussed.
\end{abstract}

\section{Introduction}

The deposition of suspended particles in the gravel matrix of river beds and its consequences to fish and invertebrate communities have received much attention in the literature (Chutter, 1969; Beschta and Jackson, 1979; Frostick et al., 1984; Berkman and Rabeni, 1987; Platts et al., 1989). Gravel spawners such as brown trout (Salmo trutta L.) and grayling (Thymallus thymallus L.) are particularly susceptible to reductions in stream bed particle size of their spawning and larval habitats (Bottom et al., 1985). Mortality of salmonid eggs is very high in areas where the river bed is subject to high levels of infiltration of fines into coarse-grained gravel (Marty et al., 1986). The compact surface of the stream bed prevents the fish from digging a redd (trout) or from injecting the eggs into the

* present address: Water and Soil Protection Laboratory of the Canton of Bern, Schermenweg 11. CH-3014 Bern. Switzerland 
gravel (grayling). Decreased interstitial flow and lower dissolved oxygen concentratiois can lead to the death of the embryo or to premature emergence of the alevin (Johnsan, 1980; Olsson and Persson, 1988). In this study we tested a method to measure $\mathrm{O}_{2}$ conce 1trations in the interstitial, realizing that a sufficiently high oxygen concentration within the gravel matrix is just one of several factors which can be attributed to successful embryonic and larval development of gravel spawners (Persat, 1970; Turnpenny \& Williams, 1982; Shirvell \& Dungey, 1983).

Many studies on the restoration of deteriorated spawning grounds for salmonids hay'e been published (i.e. Einstein and Asce, 1968; Mih and Bailey, 1981; Hermansen and Krog, 1985). However, the complex interactions of river bed morphology, hydraulic regime and sedimentation processes on one hand and the still not fully understood physiological requirements of the fish embryos and larvae in the gravel on the other hand, can make the outcome of rehabilitation work uncertain (Everest et al., 1989).

In the river High-Rhine, habitat deterioration caused by the construction and operaticn of 11 hydropower plants has left only a few areas where natural reproduction of trout ar d grayling is still possible (Gerster, 1990). These sections of the river, where loose gravel of various grain sizes dominates, coincide largely with natural hydraulic conditions. In the impounded sections of the High-Rhine, stocking with hatchery-reared grayling and brow $\mathrm{n}$ trout did not lead to a significant positive correlation between numbers of stocked ard caught fish (Gerster, 1990). Habitat restoration projects, with the long-term aim 0 reestablish self-sustaining populations of salmonids in the High-Rhine are being di ;cussed. In this study results of some preliminary investigations on the feasibility of such projects are presented.

The objectives of this study were: (1) to test whether an introduced gravel bed wou d be subject to bedload transport; (2) to monitor the infiltration of fines into the grav 21 matrix; (3) to test if an introduced gravel bed would be accepted as a spawning ground ty brown trout and grayling; (4) to test the application of dialysis porewater samplers for measuring oxygen concentrations in the gravel during egg incubation periods.

\section{Materials and methods}

The study site is situated in the impoundment Reckingen at Rhine $\mathrm{km} 79.3(\mathrm{~km} 0$ in Coilstance, Federal Republic of Germany) along the right shore, approximately $500 \mathrm{~m}$ dow11stream from the hydropower plant of Rheinsfelden/Eglisau, Switzerland (Fig. 1). The si e is not shaded by riparian vegetation. The original substrate of the littoral zone consisted mainly of small rocks (size $50-300 \mathrm{~mm}$ ). Gravel of various grain sizes filled the gaps in between. The top $15 \mathrm{~cm}$ of the river bed was clogged whereas the subsurface interstitial was loose and only slightly filled with sediments. Clogging is defined as in Cunninghaın et al., (1987). According to sports fishermen the site was a "good fishing spot" for trout. However, no reliable reports on spawning activity of any fish species were available.

In January $1990,10 \mathrm{~m}^{3}$ of washed gravel (grain size $16-50 \mathrm{~mm}$ ) were poured into the Rhine and distributed with shovels into an irregularly shaped bed of approx. $20 \mathrm{~cm}$ thicl:ness (Fig. 2). The corners were marked with iron bars to indicate possible substrate di:-iplacement. During the study period water depths over the gravel bed varied between 0.2 and $0.7 \mathrm{~m}$, depending on discharge and exact location. Water velocities (measured $3 \mathrm{cin}$ above ground with a FLOWTHERM, HöNTSCH INSTRUMENTS) ranged from 0.0510 


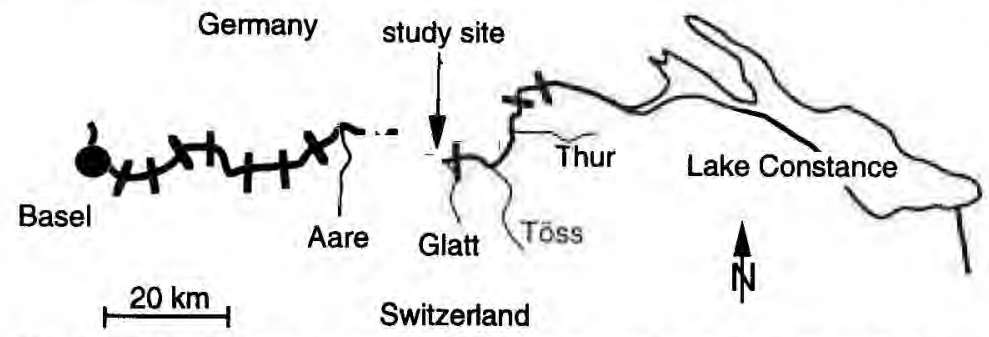

Figure 1. The river Rhine between Lake Constance and Basel ("High-Rhine"). 11 hydropower installations (marked with bars) interrupt the river continuum. The study site is situated below the power plant of Eglisau/Rheinsfelden in the impoundment of Reckingen.

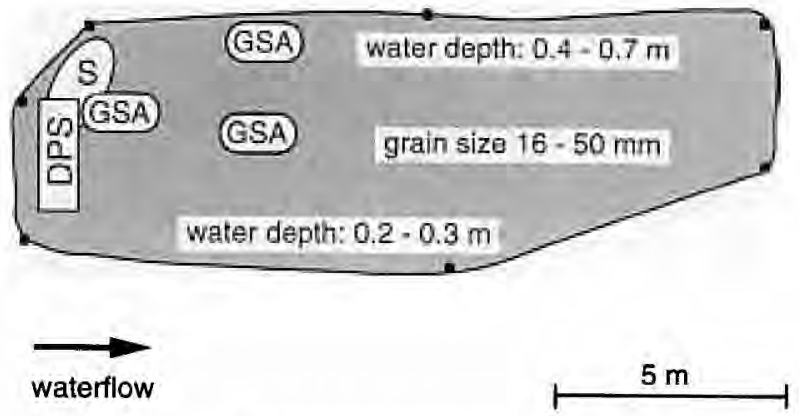

right river bank (concrete slabs)

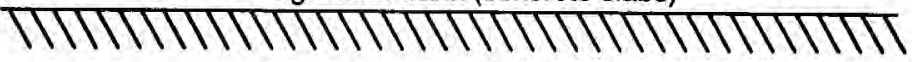

Figure 2. Plan to show the position of the artificial gravel bed (shaded area) at Rhine $\mathrm{km} 79.3 . \mathrm{S}=$ spawning site of grayling Thymallus thymallus in the springs of 1991 and 1992. DPS =location of exposed dialysis porewater samplers. GSA = sample sites for grain size analysis.

$0.45 \mathrm{~m} \cdot \mathrm{s}^{-1}$. Since no efficient and reliable quantitative method for measuring the extent of clogging (not to be confounded with analysing grain size distribution) in deeper rivers and streams exists (Schälchli, 1993), clogging of the substrate was estimated using a crowbar. Scratching the surface of the riverbed with the crowbar gave a subjective estimate on how easy it would be for a fish to move the gravel during the spawning act. Five categories of clogging were defined: no, slight, slight-moderate, moderate, moderate-heavy. These estimates were always made by the same person. The grain size of sediments $<63 \mu \mathrm{m}$ was determined with a SEDIGRAPH-2000 (MICROMERITICS).

Oxygen concentration at various depths in the gravel interstitial was measured with dialysis porewater samplers (DPS) using the equilibrium diffusion technique (Hesslein, 1976; Brandl and Hanselmann, 1991). A DPS, made of plexiglass, contained two columns of four compartments, each compartment with a volume of $14 \mathrm{~cm}^{3}$ and an exchange area of $14 \mathrm{~cm}^{2}$ (Fig. 3). The arrangement of the compartments allowed for eight individual samples in the interstitial down to a depth of $7 \mathrm{~cm}$, which was the maximum egg burial depth of grayling described by Gönczi (1989). The chambers were filled with distilled water, 


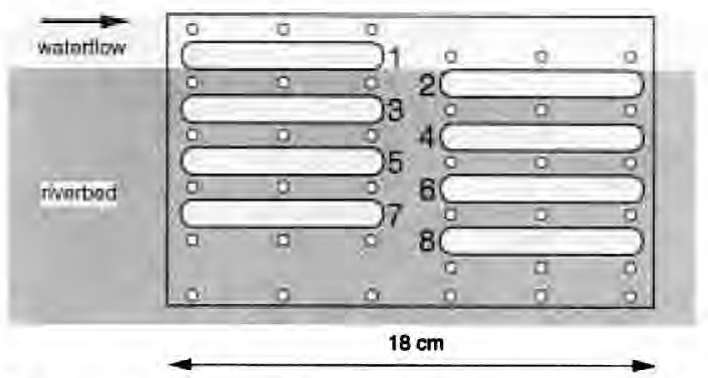

Figure 3. Side view of a dialysis porewater sampler (DPS). The core containing the eight compartments is made out of $3 \mathrm{~cm}$ thick plexiglass. The two lateral membranes (front and back), sealing off the cha nbers, are held in place with two sheets of plexiglass $(3 \mathrm{~mm})$. Compartments $2-8$ were buried in the st bstrate; compartment 1 was exposed to the open water.

covered with a membrane (HT-200 TUFFRYN, GELMAN) on both sides and kept in distilled water saturated with nitrogen until they were buried in the gravel. The samplers were placed perpendicular to the surface of the river bed, the odd numbered compartmer ts facing upstream. The top compartment (no. 1) was exposed to the open water (Fig. 1 ). Water depths above the DPS varied between 0.25 and $0.4 \mathrm{~m}$ in spring $1991,0.2$ and $0.25 \mathrm{~m}$ in winter $1991 / 92$ and 0.25 and $0.35 \mathrm{~m}$ in spring 1992 . Water velocities $3 \mathrm{~cm}$ above the samplers ranged from 0.15 to $0.25 \mathrm{~m} \cdot \mathrm{s}^{-1}$. After removal from the sediment the samples were treated within 3 minutes. Micro-Winkler and colormetrical methods were employıd to determine the oxygen concentrations.

DPSs were exposed during the spawning and incubation periods of grayling in tie spring of 1991 and 1992 and of brown trout in winter 1991/92 (Table 1). To compare inte $\mathrm{r}$ stitial oxygen concentrations in the artificial gravelbed with those in the substrate of a tributary of the Rhine, DPSs were exposed in gravel of similar size about $50 \mathrm{~m}$ below tie confluence of the river Glatt in a water depth of approximately $1 \mathrm{~m}$. The Glatt is highly polluted by anorganic and organic substances (Hydrological Yearbooks since 1974).

During the incubation period of grayling four kick samples were taken on the gravilbed in the spring of 1991 and three samples in the spring of 1992. Between December 19!91 and February 1992 five kick samples were taken during the spawning period of trout. Fish eggs and larvae were collected with a net (mesh size $1 \mathrm{~mm}$ ) and preserved in $70 \%$ alcohi)l.

Table 1. Exposure of DPSs for measuring oxygen concentration in the artificial gravel bed and in the river bed below the confluence of the River Glatt. Velocity was measured $3 \mathrm{~cm}$ above substrate

\begin{tabular}{llllll}
\hline ite & $\begin{array}{l}\text { number } \\
\text { of DPS }\end{array}$ & $\begin{array}{l}\text { duration of } \\
\text { exposure }\end{array}$ & $\Delta$ days & $\begin{array}{l}\text { water } \\
\text { depth }\end{array}$ & $\begin{array}{l}\text { mean } \\
\text { velocity }\end{array}$ \\
\hline gravelbed & 2 & $26.3 .-22.4 .1991$ & 27 & $0.30 \mathrm{~m}$ & $0.22 \mathrm{~m} \cdot \mathrm{s}^{-1}$ \\
Glatt & 2 & $26.3,-22.4 .1991$ & 27 & $1.05 \mathrm{~m}$ & $0.35 \mathrm{~m} \cdot \mathrm{s}^{-1}$ \\
gravelbed & 2 & $2.12 .91-24.2 .1992$ & 84 & $0.25 \mathrm{~m}$ & $0.21 \mathrm{~m} \cdot \mathrm{s}^{-1}$ \\
Glatt & 2 & $2.12 .91-24.2 .1992$ & 84 & $0.90 \mathrm{~m}$ & $0.25 \mathrm{~m} \cdot \mathrm{s}^{-1}$ \\
gravelbed & 4 & $27.3 .-28.4 .1992$ & 32 & $0.25 \mathrm{~m}$ & $0.20 \mathrm{~m} \cdot \mathrm{s}^{-1}$ \\
\hline
\end{tabular}


If a kick sample produced eggs, the exact location, water depth and velocity were recorded and no more sampling was done in a vicinity of $2 \mathrm{~m}$ to avoid further disturbance. In the spring of 1991 and the winter of 1991/92 the Glatt site was examined for possible spawning grounds of grayling and trout by SCUBA diving.

\section{Results}

\subsection{Stability of the gravel bed}

At the study site discharge of the Rhine has exceeded $1000 \mathrm{~m}^{3} \cdot \mathrm{s}^{-1}$ five times in the last 20 years $\left(1310 \mathrm{~m}^{3} \cdot \mathrm{s}^{-1}\right.$ in $1991,1130 \mathrm{~m}^{3} \cdot \mathrm{s}^{-1}$ in $1990,1150 \mathrm{~m}^{3} \cdot \mathrm{s}^{-1}$ in $1981,1660 \mathrm{~m}^{3} \cdot \mathrm{s}^{-1}$ in 1978 and $1240 \mathrm{~m}^{3} \cdot \mathrm{s}^{-1}$ in 1972). The mean discharge in 1990 and 1991 was $365 \mathrm{~m}^{3} \cdot \mathrm{s}^{-1}$ and $386 \mathrm{~m}^{3} \cdot \mathrm{s}^{-1}$ respectively. The two flood events during the study period, as well as several other smaller but sharp increases in discharge, did not lead to significant bedload transport. Except for a slight thinning out at the lower and the steeper midriver edge, the introduced gravel proved to be stable.

\subsection{Infiltration of fines}

Two months after introduction of the gravel, fine particles had started to infiltrate the surface layer, and the gravel was found to be slightly clogged. After 8 months, in September 1990 , it had become moderately clogged. In the spring of 1991 (exposure time 14 months) about one third of the gravel bed was covered with fines in places where low velocities prevailed. One centimeter below the surface black sediment smelling of $\mathrm{H}_{2} \mathrm{~S}$ was noticed, indicating anaerobic conditions. In May 1991 a flood $\left(Q=934 \mathrm{~m}^{3} \cdot \mathrm{s}^{-1}\right)$ washed out the fine sediments on and in the top layer and left the bed slight-moderately clogged. No indication of bedload transport was observed. As in the previous year clogging increased during the summer months and decreased again during the winter. There was a tendency towards increased clogging during the course of the 3 year study (Fig. 4). The results of-a grain size analysis taken on 19.2.1991 are shown in Table 2 . The silt fraction $(2-63 \mu \mathrm{m})$ exceeded the clay $(0-2 \mu \mathrm{m})$ fraction. This holds true for all samples.

\subsection{Spawning of trout and grayling}

No spawning of brown trout nor rainbow trout (Oncorhynchus mykiss) was observed on the gravel bed and at the Glatt site. Turbid water made it difficult at times to see any fish, and algal growth could render a redd invisible within a week. Kick samples failed to produce any eggs.

Successful spawning of grayling was documented on the gravel bed in 1990 and 1991 (Table 3). In April 1990 several adult grayling were seen on the gravel bed, but none in 1991 and 1992. No spawning behaviour could be observed in either year. In both years the spawning places were located at the upper end of the artificial gravel bed (Fig. 2). At the Glatt site neither eggs nor larvae were found. 


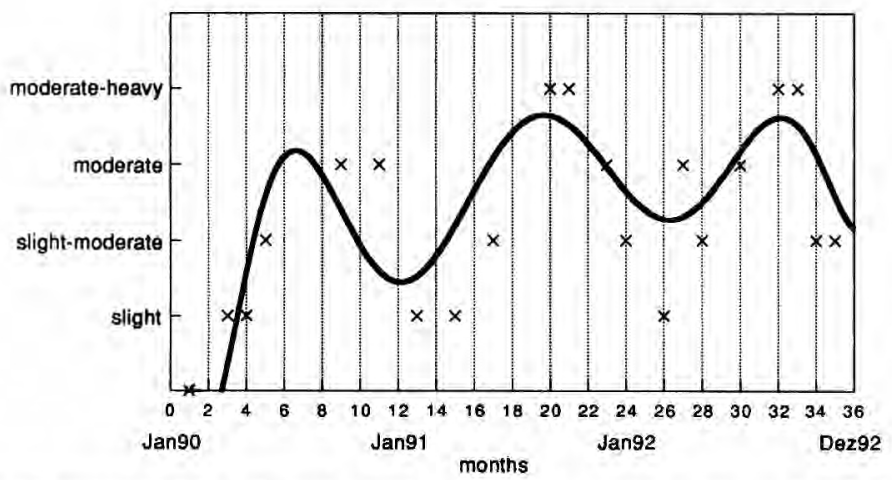

Figure 4. State of clogging of the artificial gravel bed during the course of the study. The handfitted line suggests a cyclic process with slight clogging in winter and moderate to heavy clogging in the sumn er months.

Table 2. Results of grain size analysis of three samples taken in the artificial gravel bed on 19.2. 1991. Velocity was measured $3 \mathrm{~cm}$ above substrate

\begin{tabular}{lllll}
\hline parameters & sample A & sample B & sample C & mean [\%] \\
\hline$>63 \mu \mathrm{m}$ & 32 & 45 & 20 & 32.3 \\
$2-63 \mu \mathrm{m}$ & 58 & 47 & 70 & 58.3 \\
$0-2 \mu \mathrm{m}$ & 10 & 8 & 10 & 9.3 \\
water depth $[\mathrm{m}]$ & 0.3 & 0.45 & 0.2 & 0.32 \\
velocity $\left[\mathrm{m} \cdot \mathrm{s}^{-1}\right]$ & 0.37 & 0.41 & 0.36 & 0.38 \\
\hline
\end{tabular}

Table 3. Results of kick-sampling in the artificial gravel bed. Eggs of grayling (Thymallus thymallus L.) were found in the springs of 1991 and 1992 . Water velocity was measured at the surface (first number) and $3 \mathrm{~cm}$ above substrate (second number)

\begin{tabular}{llll}
\hline samples & 16.4 .91 & 22.4 .91 & 13.4 .92 \\
\hline number of live eggs & & 8 & \\
number of dead eggs & - & - & \\
number of live larvae & - & 19 & 16 \\
water depth $[\mathrm{m}]$ & 0.2 & 0.2 & $0.4-0.5$ \\
velocity $\left[\mathrm{m} \cdot \mathrm{s}^{-1}\right]$ & $0.28 / 0.12$ & $0.25 / 0.10$ & $0.6 / 0.45$ \\
temperature $\left[{ }^{\circ} \mathrm{C}\right]$ & 11.3 & 8.8 & 8.7 \\
\hline
\end{tabular}



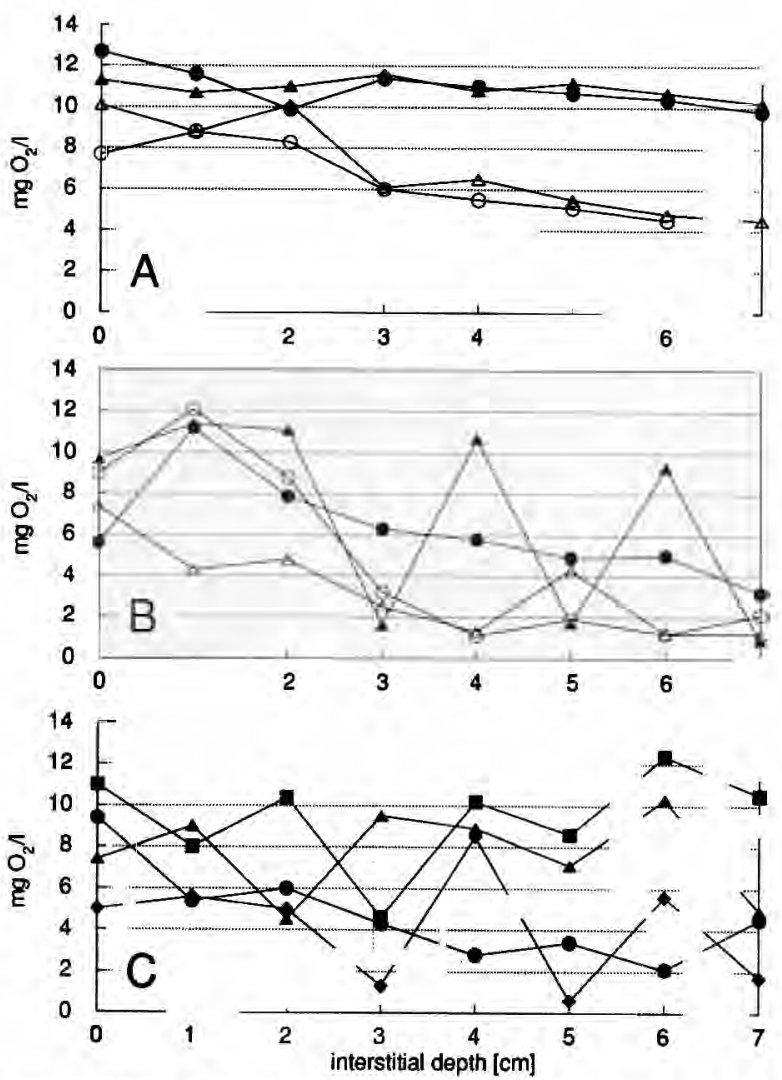

Figure 5. Oxygen concentrations at various depths in the interstital measured with dialysis porewater samplers. A = spring 1991, B = winter 1991/92, C = spring 1992 (for details of date and duration of exposure see Table 1). Filled symbols: values of the study site gravelbed; empty symbols: values of the reference site Glatt.

\subsection{Oxygen concentration in the interstitial}

In spring of 1991 only a slight decrease in oxygen concentration was measured at increasing depths of the artificial gravel bed after an exposure time of 27 days (Fig. 5A). However, a considerable decrease was measured at the polluted Glatt site where oxygen levels dropped to below $5 \mathrm{mg} \cdot 1^{-1}$. In the winter of 1991/92, after 84 days of exposure, $\mathrm{O}_{2}$ concentrations at the study site had decreased to about $4 \mathrm{mg} \cdot 1^{-1}$ at a depth of $7 \mathrm{~cm}$ in one of the DPSs. At the Glatt site the decrease was more pronounced $\left(2 \mathrm{mg} \cdot 1^{-1} \mathrm{O}_{2}\right.$ at a depth of below $4 \mathrm{~cm}$, Fig. 5B). The measured concentrations in the second DPS exposed in the gravel bed were wildly scattered between 1 and $11 \mathrm{mg} \cdot 1^{-1}$. With one exception all the high $\mathrm{O}_{2}$ levels were found in the odd numbered compartments which were located underneath each other on the same (upstream) side of the DPS (Fig. 3). In the spring of 1992, measured oxygen concentrations in the interstitial of the gravelbed again fluctuated considerably (Fig. 5C). 


\section{Discussion}

\subsection{Stability and clogging of gravel bed}

As a lake effluent, the High-Rhine would need a substantial input of bedload material by its tributaries to ensure a sufficient supply for a potential bedload transport of its own. However, due to river engineering work in the tributaries, a tendency towards increasing retention of bedloads, but not fine sediments, has been observed (Gerster, 1990). Since part of the energy of the Rhine is being,used for hydroelectric power generation, it is not surprising that in this study no bedload transport was observed.

As a direct consequence of this situation infiltration of fine sediments into the gravel matrix will lead to progressive clogging of newly introduced substrate. Even during flood events the fines will not be washed out except maybe from the top $3 \mathrm{~cm}$ of the substrate. The observed cyclic changes in the clogging of the gravel (Fig. 4) can therefore not be attributed to bedload transport. Exfiltration of groundwater during winter and the reverse action during the summer months could be a possible explanation for this phenomenon. Disturbances were also caused by our sampling procedure. However, since low levels of clogging over the entire gravel bed were found before sampling, we believe that these disturbances were of localized nature only.

\subsection{Oxygen concentrations and the spawning of fish}

In order to position the dialysis porewater samplers (DPS) the sediment structure had to be disturbed, thereby altering interstitial waterflow, oxygen supply rates and concentrations. Since concentrations were measured at the end of the exposure period and salmonids also create disturbances of the top layer of the gravel during spawning, we believe that the change in microstructure caused by burying the DPSs makes the results of these actions comparable. However, we acknowledge that it is impossible to actually simulate these complex processes.

In the spring of 1991, towards the end of the grayling spawning period, the oxygen corcentrations detected allowed for a successful embryonic and larval development in the only slightly clogged gravel bed. At the Glatt site, however, $\mathrm{O}_{2}$ concentrations were much lower and had reached a critical level of $4 \mathrm{mg} \cdot 1^{-1}$. During the trout spawning period in the winter of 1991/92 oxygen levels at both sites were low (Fig. 5B). Since sensitivity of salmonids to low levels of oxygen is greatest around hatching time $\left(\mathrm{O}_{2}\right.$ concentrations were measured at this time), we believe that successful natural reproduction was impeded or at least retarded (Alabaster and Lloyd, 1980). The longer exposure time of the DPS in winter (84 days, as compared to 27 days in spring) led to increased siltation of the interstitial and therefore reduced interstitial waterflow.

The wide range of $\mathrm{O}_{2}$ concentrations measured with one DPS in the winter of 1991/92, and with all four units in the spring of 1992, could be explained by the complexity of the gravel matrix. Depending on the microstructure in different places within the clogged interstitial, waterflow and oxygen levels can vary greatly. This can explain the high levels of $\mathrm{O}_{2}$ in the odd numbered compartments of one of the DPSs, where microconditions could have been different from those at the even numbered compartments aligned in the opposite column (Fig. 3). If this was the case, profound effects on seepage velocity, oxygen con- 
centrations and, thus, the oxygen supply rate for the fish embryo could have been the consequences.

The presence of grayling embryos and larvae in the artificial gravel bed in the springs of 1991 and 1992 demonstrated that successful natural reproduction is possible in this part of the Rhine, provided that suitable, unclogged, spawning habitats are available. However, potential spawning sites fitting this description are nonexistent or at least very scarce in the impoundment of Reckingen (Zeh, 1993).

The location of the grayling spawning places was typical (Guthruf, in prep.): it is usually situated at the upstream side of a gravel area where downwelling allows for optimal infiltration of the water into the substrate (Fig. 2). This leads to sufficient oxygen supply to and transport of metabolic waste away from the embryo. Of the total surface of the gravel bed (approximately $50 \mathrm{~m}^{2}$ ) only about $5 \mathrm{~m}^{2}$ were used as spawning sites. The remaining area was not accepted for spawning, probably due to lack of sufficient downwelling.

\section{Conclusions}

Despite the small size of the introduced gravelbed, the results of this study demonstrate some fundamental problems we are facing when evaluating habitat restoration projects in the impoundments of the High-Rhine. While the successful spawning of grayling in the gravel bed was documented in two instances, we believe that the creation of such artificial spawning areas in the impounded sections of the High-Rhine is not the ultimate solution to maintaining naturally reproducing salmonid populations. The reduced energy of the river and the resulting very small bedload transport is not sufficient for the long-term maintenance of functional spawning areas for salmonids. Infiltration of fines into the gravel matrix will soon clog newly introduced substrates. The use of machines (Mih and Bailey, 1981) or other technical means to periodically clean the gravel from sediments is discouraged as this is not consistent with the idea of a sustainable use of our resources. The insignificant number of grayling eggs found in this study is certainly not relevant for sustaining the grayling population. In order to provide sufficient spawning sites for selfsustaining salmonid populations, huge amounts of gravel would have to be dumped into the Rhine, distributed, monitored periodically and cleaned of fine sediments at least once a year. The outcome of such a costly largescale project is uncertain at best.

The construction and operation of the hydropower facilities along the High-Rhine has changed the flow regime of the river irreversibly. In accepting this situation, we must realize that the available habitat in an impoundment like Reckingen is no longer trout or grayling habitat since part of their life cycle, i.e. reproduction, is no longer possible on a scale sufficient to maintain the population. Therefore, emphasis should be given to more practicable habitat enhancement projects (e.g. creation of shallow water zones with a low gradient between aquatic and terrestrial habitats) which will favour both nonsalmonid fish species and terrestrial species (Naimann and Décamps, 1990). 


\section{ACKNOWLEDGEMENTS}

We thank B. Wehrli, EAWAG/ETH, for discussions and ideas that encouraged us to use dialysis porewater samplers in this study; C. Dinkel and A. Zwyssig, both EAWAG, for determining oxygen concentratio ss and grain size respectively; all the hardworking shovelers who turned the piles of gravel into a potential spawning ground; T. Gonser, EAWAG, for reading the manuscript. Two anonymous critical reviewers contributed valuable ideas. This study was partly financed by the SANDOZ Rheinfonds.

\section{REFERENCES}

Alabaster, J.S. and Lloyd, R., 1980. Water Quality Criteria for Freshwater Fish. FAO, Butterwortt s, London - Boston: $297 \mathrm{p}$

Berkman, H.E. and Rabeni, C.F., 1987. Effect of siltation on stream fish communities. Env. Biol. Fishes, $18 / 4: 285-294$.

Beschta, R. L. and Jackson, W. L., 1979. The intrusion of fine sediments into a stable gravel bed. J. Fish. Res. Board Can., 36:204-210.

Bottom, D.L., Howell, P. J. and Rodgers, J. D., 1985. The Effects of Stream Alterations on Salmon and Trout Habitat in Oregon. Oregon Department of Fish and Wildlife. Portland, Oregon, $70 \mathrm{p}$.

Brandl, H. and Hanselmann, K. W., 1991. Evaluation and application of dialysis porewater samplers $\mathrm{for}$ microbiological studies at sediment-water interfaces. Aquatic Sciences 53/1:55-73.

Chutter, F. M., 1969. The effects of silt and sand on the invertebrate fauna of streams and rivers. Hydr Jbiologia 34:57-76.

Cunningham, A. B., Anderson, C. J. and Bouwer, H., 1987. Effects of sediment laden flow on channel bi:d clogging. J. of Irrigation and Drainage, 1:106-118.

Einstein, H. A. and Asce, M., 1968. Deposition of suspended particles in a gravel bed. J. Hydraulics Di $/ /$, HY 5:1197-1205.

Everest, F. H., Reeves, G. H. and Sedell, J. R., 1989. Salmonid habitat: New beginnings through enhancement, but not without uncertainty, risk and failure. Proc. of Wild Trout, Steelhead and Salmon in the 21st Centrury, Portland, Oregon, July 19, 1986:9-19.

Frostick, L.E., Lucas, P.M. and Reid, I., 1984. The infiltration of fine matrices into coarse-grained all $\mathrm{I-}$ vial sediments and its implications for stratigraphical interpretation. J. geol. Soc. London, 141: 955-965.

Gerster, S., 1990. Veränderungen der Fischbestände am Hochrhein und deren Ursachen. Auftragsarbı it zuhanden BUWAL, Bern. $287 \mathrm{p}$.

Gönczi, A.P., 1989. A study of physical parameters at the spawning sites of the European grayling (Thymallus thymallus L.). Regulated Rivers: Research \& Management, 3:221-224.

Guthruf, J. (in prep.). Populationsbiologische Untersuchungen über die Äsche in der Aare und Glârie. Dissertation, ETH Zürich.

Hermansen, H. and Krog, C., 1985. A review of brown trout (Salmo trutta) spawning beds, indicatiltg methos for their re-establishment in Danish lowland rivers. In: Alabaster, J.S. (ed.) Habitat Modification and Freshwater Fisheries. EIFAC Proc., FAO, Butterworths, London - Boston: 116-123.

Hesslein, R. H., 1976. An in situ sampler for close interval pore water studies. Limnol. Oceanogr. 21: 912-914.

Hydrological Yearbooks (since 1974). Publisher: Landeshydrologie- Geologie, Bern.

Johnson, R. A., 1980. Oxygen Transport in Salmon Spawning Gravels. Can. J. Fish. Aquat. Sci., 37: $155-162$.

Marty, C., Beall, E. and Parot, G., 1986. Influence de quelques paramètres du milieu d'incubation sur la survie d'alevins de saumon atlantique, Salmo salar, en ruisseau expérimental. Int. Revue ges. Hydrobiol. 71/3:349-361.

Mih, W. C. and Bailey, G.C., 1981. The Development of a Machine for the Restoration of Stream Grav el for Spawning and Rearing of Salmon. Fisheries, 6/6:16-20.

Naiman, R.J. and Décamps, H., 1990. Ecology and management of aquatic - terrestrial ecotont:s. UNESCO, Paris, $316 \mathrm{p}$.

Olsson, T. I. and Persson B.G., 1988. Effects of deposited sand on ova survival and alevin emergence in brown trout (Salmo trutta L.). Arch. Hydrobiol., 113/4:621-627. 
Persat, H., 1970. Ecologie de l'ombre commun. Bull. franç. piscicult. 266:11 -20.

Platts, W. S., Torquemada, R. J., McHenry, M. L. and Graham, C. K., 1989. Changes in Salmon Spawning and Rearing Habitat from Increased Delivery of Fine Sediment to the South Fork Salmon River, Idaho. Trans. Am. Fish. Soc. 118:274-283.

Schälchli, U., 1993. Die Kolmation von Fliessgewässersohlen: Prozesse und Berechnungsgrundlagen. Dissertation Nr. 10293 ETH Zürich.

Shirvell, C.S. and Dungey, R. G., 1983. Microhabitats Chosen by Brown Trout for Feeding and Spawning in Rivers. Trans. Am. Fish. Soc. 112, 3:355-367.

Tumpenny, A.W.H. and Williams, R., 1982. A conductiometric technique for measuring the water velocity in salmonid spawning beds. Water Res. 16:1383-1390.

Zeh, M., 1993. Reproduktion und Bewegungen einiger ausgewählter Fischarten in einer Staustufe des Hochrheins. Dissertation Nr. 10288 ETH Zürich.

Received 3 December 1992;

revised manuscript accepted 25 October 1993. 